\title{
Impact of pH, Dissolved Inorganic Carbon, and Polyphosphates for the Initial Stages of Water Corrosion of Copper Surfaces Investigated by AFM and NEXAFS
}

\author{
Brian R. Lewandowski, ${ }^{1}$ Kathie L. Lusker, ${ }^{1}$ Zorabel M. LeJeune, ${ }^{1}$ \\ Darren A. Lytle, ${ }^{2}$ Pingheng Zhou, ${ }^{3}$ Phillip T. Sprunger ${ }^{4}$ and Jayne C. Garno ${ }^{1 *}$ \\ ${ }^{1}$ Department of Chemistry, Louisiana State University, Baton Rouge, LA 70803 \\ ${ }^{2}$ National Risk Management Research Laboratory, Water Supply and Water Resources Division of the United States \\ Environmental Protection Agency, Cincinnati, OH 45268 \\ ${ }^{3}$ Center for Advanced Microstructures and Devices (CAMD), Louisiana State University, Baton Rouge, LA 70806 \\ ${ }^{4}$ Department of Physics and Astronomy, Louisiana State University, Baton Rouge, LA 70803
}

Corresponding Author: Jayne C. Garno, Associate Professor, Chemistry Department, Louisiana State University

232 Choppin Hall, Baton Rouge, LA 70803,

Phone: 225-578-8942,FAX:225-578-3458,e-mail:.jgarno@lsu.edu

doi:10.5618/chem.2011.v1.n1.3 || Received: 22-04-2011, Accepted: 25-05-2011, Available online: 27-05-2011

\begin{abstract}
Nanoscale studies at the early stages of the exposure of copper surfaces after systematic treatments in synthesized water solutions can provide useful information about corrosion processes. The corrosion and passivation of copper surfaces as influenced by $\mathrm{pH}$, dissolved inorganic carbon (DIC) and polyphosphate levels were investigated with nanoscale resolution, to gain insight about changes in surface morphology and the composition of adsorbates. Information regarding the surface morphology after chemical treatment was provided by atomic force microscopy (AFM) and the corresponding chemical composition of treated surfaces was obtained with near-edge $X$-ray absorption fine structure (NEXAFS). Changes in the surface topography of copper samples were readily detected within only 6 to 24 hours of exposure to water solutions. Topographic views of surface changes are presented to compare the growth of adsorbate layers that take place during the evolution of mineral deposits. Slight changes in the $\mathrm{pH}$ and concentrations of phosphates in the water samples have a substantial impact on the rate of growth and composition of surface
\end{abstract}

deposits. These studies provide insight on the mechanisms and resulting chemical constituents that lead to surface passivation or corrosion of copper, simulating conditions that occur in water distribution systems.

Keywords: copper; corrosion; AFM; NEXAFS; polyphosphates; dissolved inorganic carbon.

\section{Introduction}

The degradation of metal pipelines in water distribution systems caused by corrosion is a valuable research focus for efforts to minimize corrosion and reduce the release of deleterious metals into drinking water. The mechanisms of aqueous corrosion of copper as impacted by various combinations of anions such as chloride, sulfate, bicarbonate, silicate, phosphate and calcium have not been thoroughly investigated, particularly at the nanoscale. Studies of the early stages of water corrosion occurring for a copper surface $(<24 \mathrm{~h})$, as specifically influenced by changing $\mathrm{pH}$, ions and orthophosphate levels will provide insight towards developing water 
treatment chemistries which minimize the corrosive effects of water on metal distribution systems.

Copper originates naturally in rock, soil, water, sediment, and air, and is commonly used for water pipes in household plumbing. Corrosion of metal plumbing in water distribution pipelines, valves, and fixtures leads to the release of copper ions into water samples and produces deposits of mineral by-products on the interior walls of metal pipes. Corrosion can be detrimental to the quality of public drinking water, by releasing metals such as copper into water. Though a small amount of copper is required by the human body as an essential nutrient, long-term exposure to elevated levels of copper in drinking water may cause serious health problems. ${ }^{1}$ Ingestion of high levels of copper have been shown to cause acute effects of gastrointestinal disturbance, whereas drinking water containing elevated levels of copper over many years may cause chronic damage to the liver or kidneys. In 1991, the United States Environmental Protection Agency (USEPA) published the Lead and Copper Rule in the National Primary Drinking Water Regulations (also referred to as the LCR or 1991 Rule). These regulations require that lead and copper levels in drinking water be minimized in public water utilities. For copper, an action level of $1.3 \mathrm{mg} / \mathrm{L}$ was established for water samples standing for more than six hours.

Orthophosphate and increased concentrations of dissolved inorganic carbon (DIC) in water samples were found to prevent the initiation of localized corrosion. ${ }^{2}$ Pitting corrosion of copper piping occurred in specific water conditions with low chlorine concentrations and DIC concentrations of 5 and $10 \mathrm{mg} / \mathrm{L}$. Phosphorous compounds often are used to inhibit corrosion and to protect metal surfaces. ${ }^{3-7}$ Phosphates inhibit copper corrosion by producing a passivating film or protective scale layer on surfaces. ${ }^{8,9}$ Orthophosphate and hexametaphosphate have been shown to reduce the soluble copper release from corrosion by-products. ${ }^{10}$ Aminophosphonic acid has also been shown to inhibit corrosion of iron surfaces. ${ }^{11}$

Atomic force microscopy (AFM) has previously been applied for corrosion studies to gain insight on local changes of metal surfaces. For example, in situ studies of corrosion inhibitors were investigated for different media using AFM. ${ }^{12-16}$ Surface studies with AFM have been used to investigate corrosion of materials such as copper, ${ }^{8,17-20}$ steel, $^{21,22}$ iron $^{23,24}$ and silver. ${ }^{25}$ Studies with AFM provide 3D topographic information for a wide range of surface materials with micron to nanometer resolution. High resolution AFM provides sensitive measurements for systematically investigating changes, enabling one to control a wide range of experimental parameters for surface treatments. Near-edge X-ray absorption fine structure (NEXAFS) has been used to evaluate the oxidation state of copper surfaces, for example, to differentiate $\mathrm{CuO}$ and $\mathrm{Cu}_{2} \mathrm{O} \cdot{ }^{26}$ The evolution of oxides can be sensitively detected using NEXAFS for complementary information of samples treated with various water chemistries.

Reproducible experiments should be designed to evaluate the effects of drinking water chemistries on the corrosion of copper pipes. Corrosion of copper surfaces by water is a process that involves multiple parameters. ${ }^{27-31}$ Previously, we studied the effects of phosphates as a function of $\mathrm{pH}$ for mitigating the corrosion of copper. ${ }^{8}$ Essentially, the previous report provides control experiments as a baseline for designing further studies of different water parameters. In the new studies to be disclosed in this article, we have designed experiments to study the effects of $\mathrm{pH}$ and polyphosphate levels combined with much higher levels of DIC. Treated surfaces were examined using analyses with AFM and NEXAFS to obtain details of the mechanisms of corrosion and passivation of copper surfaces. Differences in the structure and morphology of copper samples were readily observed within 6 to 24 hours of exposure to water of designed chemical composition which mimic drinking water supplies. At different $\mathrm{pH}$ levels, substantial differences in morphology were observed at the nanoscale, for surfaces treated within the normal $\mathrm{pH}$ range and ion levels of common tap water. Moreover, changes for the nearsurface chemical composition after 24 hour exposure were obtained with NEXAFS spectroscopy. Water chemistry parameters were selected to simulate conditions for the typical range of values for drinking water.

\section{Materials and Methods}

\subsection{Surface preparation.}

Scanning probe studies require surfaces which are clean and relatively smooth for viewing small changes. The samples used in these experiments were pure copper $(99.9 \%)$ cut into $1 \times 1$ in $^{2}$ square pieces. To remove surface contaminants, copper samples were cleaned by sonication for 5 minutes in $0.5 \%$ detergent solution (Triton X-100, Curtis Matheson Scientific, Inc., Houston, TX). Next, the samples were cleaned in an ultrasonic bath for 5 minutes with deionized water (Milli-Q, 18 megohm). After sonication, the copper surfaces were rinsed in acetone and dried in air. The copper samples were not polished or subjected to extensive chemical cleaning procedures so as to mimic the conditions of the surface of natural copper pipe materials. 


\subsection{Water sample preparation.}

The water conditions used for these experiments are summarized in Table 1. The $\mathrm{pH}$ of the solutions was controlled with an automated titration system using hydrochloric acid and sodium hydroxide (Fisher Scientific). Reagents added to the solutions were sodium bicarbonate, sodium sulfate, sodium chloride, sodium hypochlorite (Fisher Scientific), and sodium hexametaphosphate (Mallinckrodt Chemicals). Initial concentrations were verified using inductively coupled plasma atomic emission spectrophotometry.

Table 1. Water conditions for copper sample immersion.

\begin{tabular}{lllllll}
\hline Sample & $\mathrm{pH}$ & $\begin{array}{l}\text { DIC } \\
(\mathrm{mg} / \mathrm{L})\end{array}$ & $\begin{array}{l}\text { Sulfate } \\
(\mathrm{mg} / \mathrm{L})\end{array}$ & $\begin{array}{l}\text { Chloride } \\
(\mathrm{mg} / \mathrm{L})\end{array}$ & $\begin{array}{l}\text { Chlorine } \\
(\mathrm{mg} / \mathrm{L})\end{array}$ & $\begin{array}{l}\text { Hexametaphosphate } \\
(\mathrm{mg} / \mathrm{L})\end{array}$ \\
\hline 1 & 9 & 100 & 120 & 60 & 3 & 0 \\
2 & 6.5 & 100 & 120 & 60 & 3 & 0 \\
3 & 9 & 10 & 120 & 60 & 3 & 6 \\
4 & 6.5 & 10 & 120 & 60 & 3 & 6 \\
\hline
\end{tabular}

\subsection{Experimental Setup.}

Copper samples were immersed in $1 \mathrm{~L}$ of water sample by suspension with a nylon string. The solutions were stirred at a slow rate and covered with parafilm to simulate low flow conditions in a water pipe. After either 6 or $24 \mathrm{~h}$ immersion, the samples were removed and dried in air for analysis using AFM. Thereafter, NEXAFS spectra were subsequently acquired after $24 \mathrm{~h}$ of immersion.

\subsection{Atomic force microscopy.}

An Agilent 5500 scanning probe microscope equipped with Picoscan v5.4 software (Agilent Technologies, Tempe, AZ) was used for AFM studies. Digital images were processed using Gwyddion (version 2.9) open source software, which is freely available on the Internet and supported by the Czech Metrology Institute. ${ }^{32}$ Images were acquired in ambient conditions using tapping mode. Probes were obtained from Nanosensors (Neuchatel, Switzerland), and had average resonance frequencies ranging from $155-170 \mathrm{kHz}$.

\subsection{Near-edge $X$-ray absorption fine structure.}

Measurements with NEXAFS were performed at the Center for Advanced Microstructures and Devices (CAMD) synchrotron's variable-line-space planegrating-monochromator (VLSPGM) beamline. ${ }^{33}$ The tunable incident radiation, with a resolution of better than $0.2 \mathrm{eV}$ at the copper L-edge, is focused onto the samples located in a UHV chamber. The photon energy scale was calibrated with copper standard samples $(\mathrm{CuO}$ and $\mathrm{Cu}$ ). The incident beam intensity was concurrently monitored by a gold mesh placed in the incident beam before the sample. The measured sample spectrum $I_{0}$ (total electron yield mode) was normalized by the total electron yield of the gold mesh. Reproducibility of the spectra was carefully monitored and verified by multiple scanning, typically four times. NEXAFS spectra were acquired at room temperature at both the oxygen K-edge and the copper L-edge regions.

\section{Results}

Studies of the early stages of water corrosion, as specifically influenced by selected parameters of $\mathrm{pH}$, anions and orthophosphate levels were accomplished by immersing cleaned pieces of copper in various water samples for either 6 or $24 \mathrm{~h}$. After samples were removed and dried, AFM images were used to directly visualize the nucleation and growth of metal deposits, corrosion by-products or the formation of pits. Topographic views of samples that were prepared under controlled aqueous conditions provide insight for the role of $\mathrm{pH}$ and water parameters for the passivation or corrosion events which take place at the onset of copper corrosion. Thereafter, NEXAFS data was acquired on the $24 \mathrm{~h}$ immersion samples to qualitatively determine the near-surface chemical compositions.

\subsection{Cleaned copper sample before immersion in water.}

A control sample of untreated copper was characterized to provide a frame of reference for surface changes. Topographic AFM images were acquired for a cleaned copper sample without water immersion as shown in Figure 1. Vertical grooves or scratches aligned in a vertical direction are shown in the successive zoom-in views of Figures $\mathbf{1 A}$ to $\mathbf{1 C}$, which measure different depths ranging from 1 to $15 \mathrm{~nm}$. The grooves are spaced 
at variable intervals, spanning distances from 1 to several microns. There are also small pits and scars scattered randomly throughout the sample surface, which contribute to a moderately rough surface from the nanoscale perspective. All of the AFM images acquired for subsequent samples in this report were oriented to view a similar vertical direction, to enable convenient comparison. Multiple areas of the samples were analyzed, and the views shown in Figure $\mathbf{1}$ are representative of the morphology for areas throughout the entire copper surface. The image of Figure 1C is slightly distorted by digital noise because it was acquired at the lower limit of the 100 micron range of the wide area scanner. The RMS roughness for a selected small region of Figure 1C measures $2.4 \mathrm{~nm}$, which is comparable to previous reports of surface roughness for copper surfaces. ${ }^{34}$
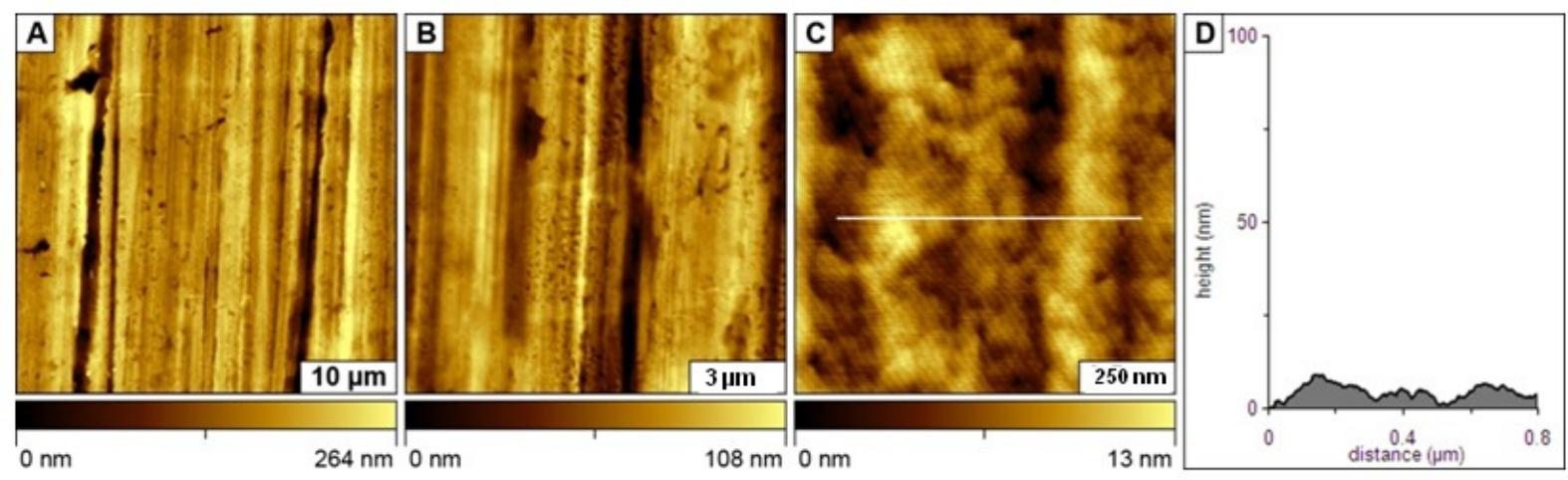

Figure 1. Surface views of a copper reference sample that was cleaned by sonication. Tapping mode topographs for areas of (A) $40 \times 40 \mu \mathrm{m}^{2}$; (B) $12 \times 12 \mu \mathrm{m}^{2}$; (C) $1 \times 1 \mu \mathrm{m}^{2}$ electronic noise causes the diagonal line patterns; (D) cursor profile for the line in $\mathbf{C}$.

\subsection{Effects of high carbonate alkalinity at $\mathrm{pH} 6.5$ versus 9.}

Dissolved inorganic carbon represents the sum of inorganic carbon species and includes contributions of carbon dioxide, carbonic acid, bicarbonate and carbonate anions. Most of the total alkalinity of natural waters result from the carbonate alkalinity of DIC. Since natural and drinking waters have at least minimal levels of DIC, it would not be practical to test samples in water without DIC present. Therefore, our experiments were designed to have at least $10 \mathrm{mg} / \mathrm{L}$ DIC as a baseline reference. In previous reports, alkalinity has been shown to mitigate the corrosive effects of water and protect copper surfaces. ${ }^{2}$ For a direct assessment of the effects of high alkalinity on copper surfaces, water sample 1 was prepared at $\mathrm{pH} 9$ with a relatively high DIC level of $100 \mathrm{mg} / \mathrm{L}$. Successive zoom views of the copper surface after 6 and $24 \mathrm{~h}$ at high alkalinity are presented in Figure 2, in which the DIC originated from dissolved sodium bicarbonate. The top row (Figures 2A-2D) shows the surface changes after immersion for $6 \mathrm{~h}$, and the bottom row (Figures 2E-H) shows the changes in topography after $24 \mathrm{~h}$. The images disclose scattered arrangements of round protrusions or clusters of carbonate by-products, formed at the surface-liquid interface. There was no evidence of pits or holes being formed within this time frame, and successive magnified views of Figures $\mathbf{2 B}$ and $\mathbf{2 C}$ reveal that the entire surface is covered with regular sized clusters ranging from 25 to $63 \mathrm{~nm}$. A representative line profile in Figure 2D indicates the heights for two large adsorbates measure 48 and $55 \mathrm{~nm}$. The overall roughness of the sample has increased; the area in Figure 2C evidenced an RMS roughness measuring $13 \mathrm{~nm}$.

After $24 \mathrm{~h}$ immersion in water sample 1, the surfaces display similar morphologies of random protrusions of carbonate clusters, however at higher density. A few larger clusters have attached to the surface, exhibiting heights ranging from 48 to $135 \mathrm{~nm}$. The taller adsorbates are actually aggregates of smaller clusters, as revealed in the zoom-in AFM views of Figures $2 \mathbf{F}$ and 2G. A representative cursor profile across Figure 2G shows that the heights of the surface protrusions have increased in size, in comparison to Figure 2C. 

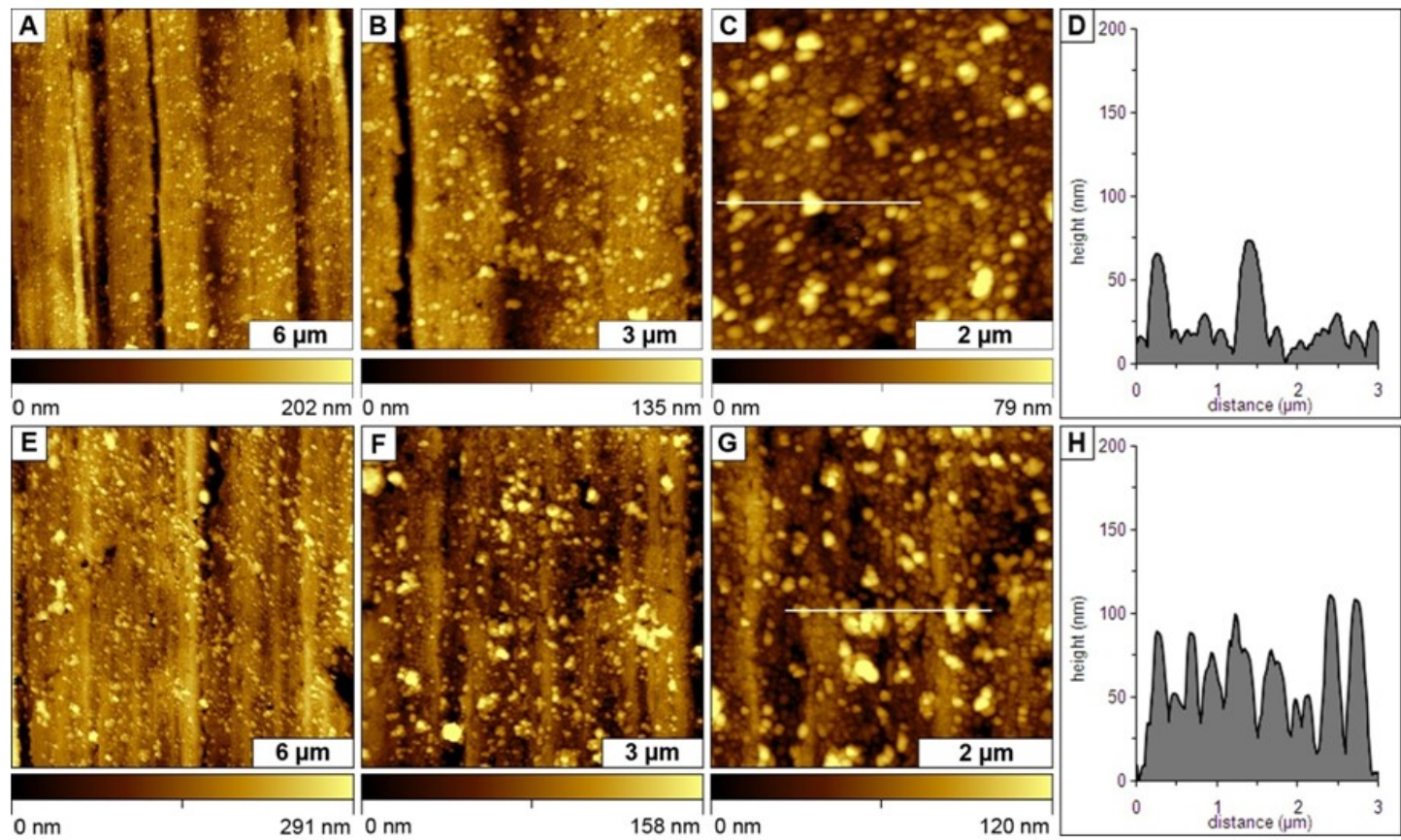

Figure 2. Copper surface after immersion in water sample 1 at pH 9 with $100 \mathrm{mg} / \mathrm{L}$ DIC. Successive magnified views after $6 \mathrm{~h}$ for (A) $20 \times 20 \mu \mathrm{m}^{2}$; (B) $10 \times 10 \mu \mathrm{m}^{2}$; (C) $5 \times 5 \mu \mathrm{m}^{2}$; (D) line profile for C. Changes after $24 \mathrm{~h}$ for areas of (E) $20 \times 20 \mu \mathrm{m}^{2}$; (F) $10 \times 10 \mu \mathrm{m}^{2}$; (G) $5 \times 5 \mu \mathrm{m}^{2}$; (H) line profile for $\mathbf{G}$.
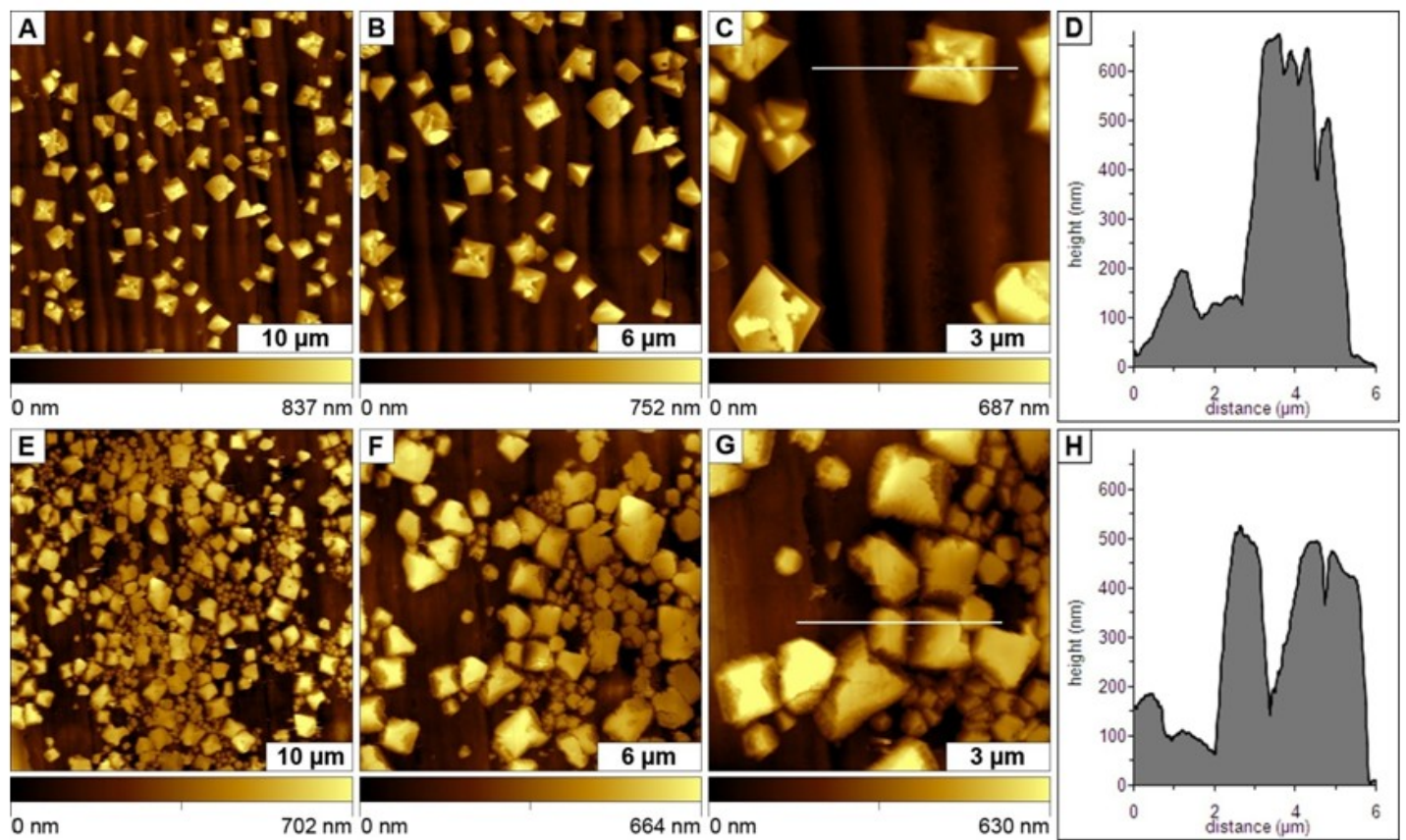

Figure 3. Surface changes of copper substrate after immersion in water sample 2 at $\mathrm{pH} 6.5$ and $100 \mathrm{mg} / \mathrm{L} \mathrm{DIC}$. AFM topographs after immersion for $6 \mathrm{~h}$ for areas of (A) $30 \times 30 \mu \mathrm{m}^{2}$; (B) $20 \times 20 \mu \mathrm{m}^{2}$; (C) $10 \times 10 \mu \mathrm{m}^{2}$; (D) line profile for C. Similarly prepared sample after $24 \mathrm{~h}$ immersion for areas of (E) $40 \times 40 \mu \mathrm{m}^{2}$; (F) $20 \times 20 \mu \mathrm{m}^{2}$; (G) $10 \times 10 \mu \mathrm{m}^{2} ;(\mathrm{H})$ line profile for $\mathbf{G}$. 
Water sample 2 was prepared to match the ion composition of sample 1; however, the $\mathrm{pH}$ was adjusted to 6.5 to enable a direct comparison of $\mathrm{pH}$ effects for copper surfaces exposed to high DIC levels. There are considerable differences in surface morphology after immersion in water sample 2, as shown in the AFM topographs of Figure 3. The upper row (Figures 3A-D) displays results for a sample that was immersed for $6 \mathrm{~h}$ in water sample 2, and the second row (Figures 3E-H) shows the changes after $24 \mathrm{~h}$ immersion. Large, angular crystalline nanostructures are evident for the sample prepared at $\mathrm{pH}$ 6.5. The large crystals shown in the upper row of images have heights ranging from 432 to $723 \mathrm{~nm}$, and cover approximately $20 \%$ of the surface. The RMS roughness has increased to $164 \mathrm{~nm}$. The facets and angular morphology of the crystals can be readily recognized as salt crystals resulting from the precipitation of sodium salts at lower $\mathrm{pH}$.

After $24 \mathrm{~h}$ immersion in water sample 2, the surface coverage and density of crystals has increased in comparison to the $6 \mathrm{~h}$ sample. The heights of the structures range from 210 to $580 \mathrm{~nm}$ and the surface coverage has increased to approximately $56 \%$ of the total area. The RMS roughness of the $24 \mathrm{~h}$ sample measured $166 \mathrm{~nm}$.

\subsection{Surface changes with addition of hexameta-} phosphate at pH 6.5 and 9.

When hexametaphosphate was added to the synthetic water samples, at a lower alkalinity level of $10 \mathrm{mg} / \mathrm{L}$ DIC, considerably different morphologies were observed for the copper surfaces. Figure $\mathbf{4}$ displays images of the morphology changes for a copper surface immersed in water sample $3(\mathrm{pH} 9,6 \mathrm{mg} / \mathrm{L}$ hexametaphosphate, $10 \mathrm{mg} / \mathrm{L}$ DIC). The top row (Figures 4A-B) shows a sample that was immersed for $6 \mathrm{~h}$ in water sample 3, and the bottom row of images (Figures 4D-E) has views of a sample immersed for 24 h. After $6 \mathrm{~h}$ of sample immersion, round plateau-like features become apparent in Figure 4A; however, these structures appear to be protrusions that are integrated within the surface and are derived from the copper landscape. The lateral dimensions of the round plateaus measure as large as 0.72 to $1.25 \mu \mathrm{m}$ in size. The protrusions do not appear to be attached to the surface, rather, a predominant surface coverage of pits and valleys have become evident in the zoom-in views of Figure 4B. The small pits in this image have depths of 18 to $50 \mathrm{~nm}$. The surface morphologies reveal the onset of changes attributable to pitting corrosion. The RMS roughness for the topograph of Figure 4B measures 11 $\mathrm{nm}$.

After $24 \mathrm{~h}$ immersion in water sample 3, the pitting became more predominant and clearly apparent throughout areas of the surface (Figure 4D and 4E). Instead of the relatively smooth, continuously flat surface of the control sample in Figure 1 (RMS roughness measured $2.4 \mathrm{~nm}$ ), the surface areas show a high density of multiple pits and valleys have formed. There is no evidence of loosely attached adsorbates or deposits formed for these water conditions, rather the surface exhibits the shapes of valleys and protrusions throughout the sample areas. The evidence of pitting is especially visible in Figure 4D when placed side-byside with a comparable area of the control sample of Figure 1B. The line profile of Figure 4F indicates the overall surface corrugation. The roughness after $24 \mathrm{~h}$ measured $15 \mathrm{~nm}$ for the surface immersed in water sample 3 .

The effects of hexametaphosphate for treating a copper surface at $\mathrm{pH} 6.5$ (6 mg/L hexametaphosphate, $10 \mathrm{mg} / \mathrm{L} \mathrm{DIC}$ ) are shown in the AFM images of Figure 5. The upper images (Figures $\mathbf{5 A}$ and $\mathbf{5 B}$ ) display changes for a sample immersed in water sample 4 for 6 $h$ and the bottom row (Figures 5D and 5E) presents views for a sample immersed under the same conditions for $24 \mathrm{~h}$. After $6 \mathrm{~h}$ immersion, the surface displays both the appearance of surface deposits as well as an increase in pitting corrosion. Round adsorbates of various sizes and shapes have formed throughout areas of the copper surface. Pitting is also evident for the zoom-in view of Figure 5B, evidencing a continuous coverage of the surface with small pits that are 20-40 nm deep. The globular nanostructures measure 25 to $60 \mathrm{~nm}$ in dimension, and the overall RMS roughness measured 14 $\mathrm{nm}$ for the area framed in Figure 5B.

A different surface morphology is evident after immersion in water sample 4 for $24 \mathrm{~h}$. The smooth globular shapes have been replaced with compact clusters of aggregated nanoparticles, as well as an increase in depth and density for pinhole pits (Figure 5D). The surface changes result from the interplay of corrosive etching and the adsorption of nanoparticle deposits. From the zoom-in view presented in Figure $\mathbf{5 E}$, there are many aggregated clusters of small adsorbates attached at the sites of grooves and crevices on the surface. The clusters of nanoparticles measure from 15 to $71 \mathrm{~nm}$ in height, and the RMS roughness increased to $22 \mathrm{~nm}$ (Figure 5E). 


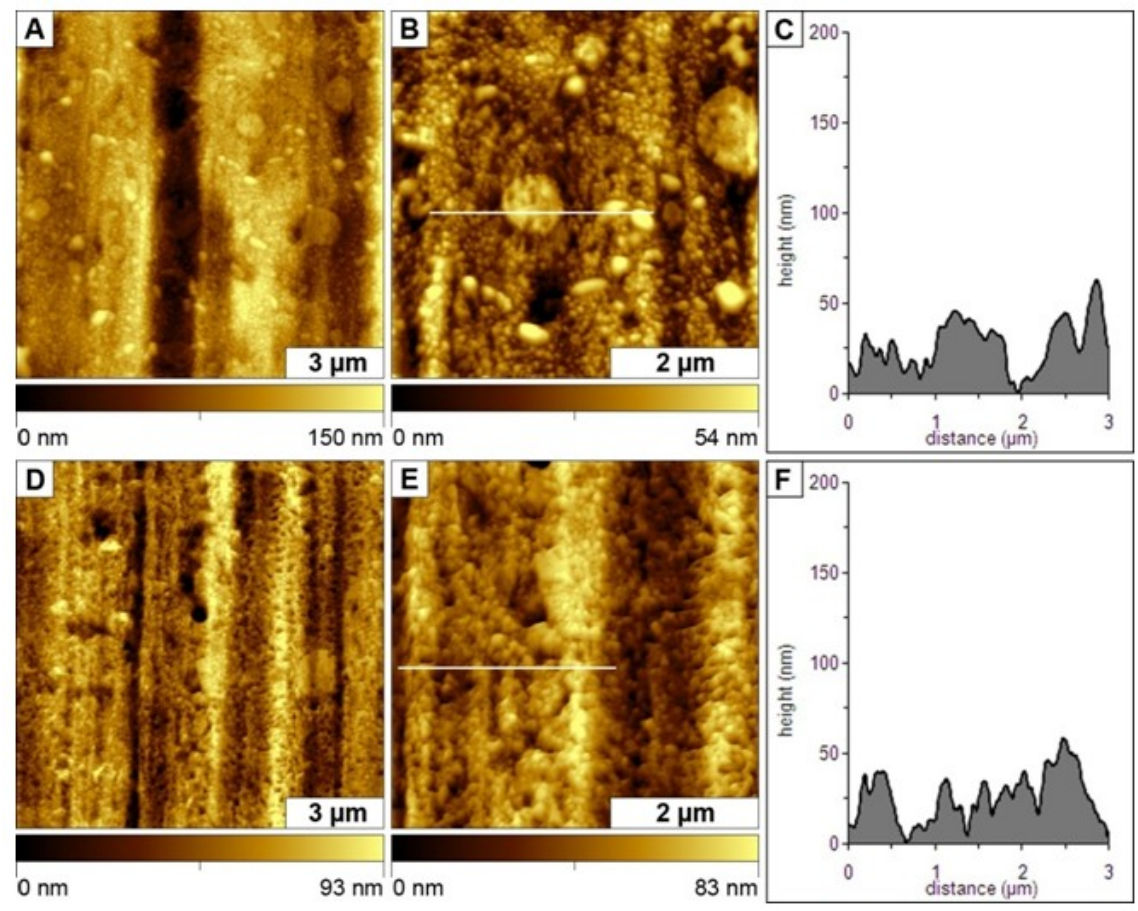

Figure 4. Copper surface after immersion in water sample 3 at pH 9 with $6 \mathrm{mg} / \mathrm{L}$ hexametaphosphate and $10 \mathrm{mg} / \mathrm{L}$ DIC. Surface views after $6 \mathrm{~h}$ for areas of (A) $11 \times 11 \mu \mathrm{m}^{2}$; (B) $5 \times 5 \mu \mathrm{m}^{2}$; (C) line profile for B. After $24 \mathrm{~h}$ of immersion: (D) $11 \times 11 \mu \mathrm{m}^{2}$; (E) $5 \times 5 \mu \mathrm{m}^{2}$; (F) line profile for $\mathrm{E}$.
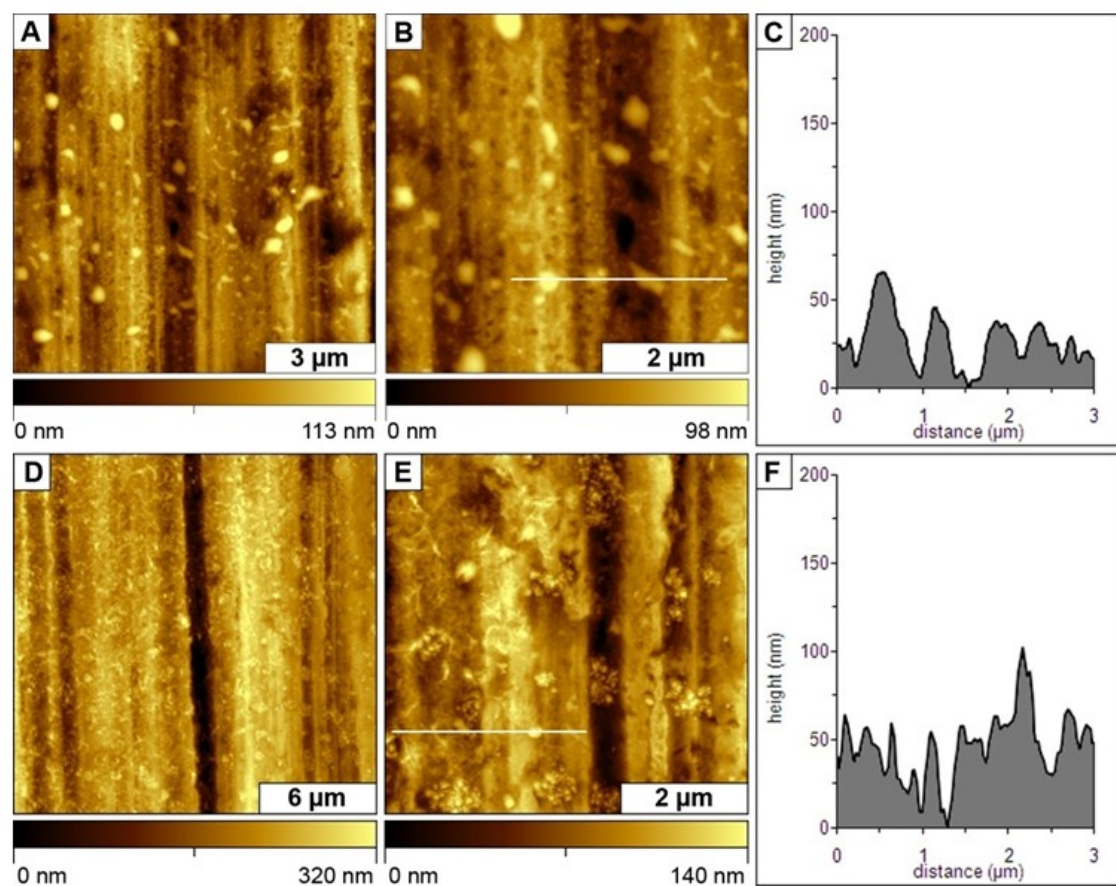

Figure 5. Changes of copper surface after immersion in water sample 4 at $\mathrm{pH} 6.5$ with addition of $6 \mathrm{mg} / \mathrm{L}$ hexametaphosphate and $10 \mathrm{mg} / \mathrm{L}$ DIC. Surface changes after $6 \mathrm{~h}$ for (A) $10 \times 10 \mu \mathrm{m}^{2}$; (B) $5 \times 5 \mu \mathrm{m}^{2}$; (C) line profile for B. After $24 \mathrm{~h}$ of exposure, areas are shown for (D) $18 \times 18 \mu \mathrm{m}^{2}$; (E) $5.6 \times 5.6 \mu \mathrm{m}^{2}$; (F) line profile for $\mathbf{E}$. 


\subsection{Identification of chemical composition of copper solids with NEXAFS.}

Total electron yield NEXAFS data probes the chemical composition within the near surface region $(<$ $10-20 \mathrm{~nm}$ ). Subtle differences in copper chemical species between the clean and treated samples are shown in Figure 6. As a reference, Figure 6F shows a spectrum of the $\mathrm{CuO}$ standard characterized by two relatively intense features at 931 and $951 \mathrm{eV}$. The peaks arise from the dipole transitions of the $\mathrm{Cu} 2 \mathrm{p}_{3 / 2}\left(\mathrm{~L}_{\mathrm{III}}\right)$ and $\mathrm{Cu} 2 \mathrm{p}_{1 / 2}\left(\mathrm{~L}_{\mathrm{II}}\right)$ into the empty d-states. The smaller peak around $940 \mathrm{eV}$ is a shake-up (multielectron excitation) satellite. Similarly, the as-prepared clean copper sample, corresponding to Figure 1, shows intense features at 934 and $954 \mathrm{eV}$, indicating $\mathrm{Cu}(0)$ and/or $\mathrm{Cu}(\mathrm{I})$. The width of this peak is larger than in situ sputtered pure $\mathrm{Cu}$, indicating some degree of surface chemistry (e.g.

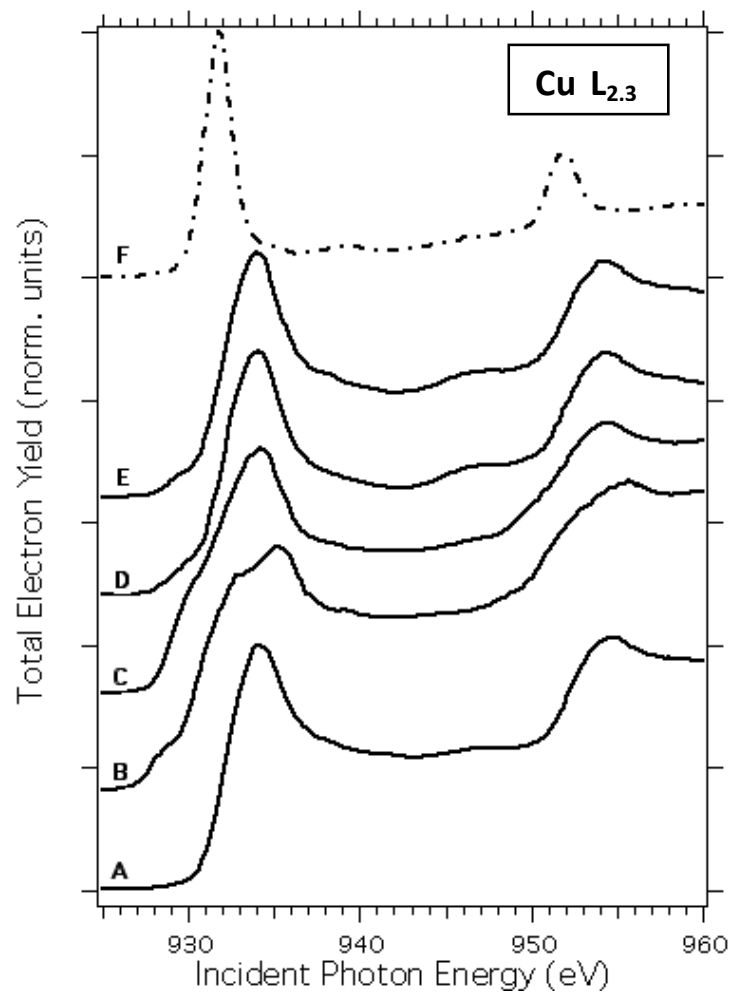

Figure 6. Total electron yield NEXAFS spectra of the different treated samples in the energy range of the $\mathrm{Cu}$ $\mathrm{L}_{2,3}$ absorption edge: (A) clean copper surface. Changes of copper surface after immersion in water for $24 \mathrm{~h}$ at (B) $\mathrm{pH} 9$ with $100 \mathrm{mg} / \mathrm{L}$ DIC (sample 1); (C) $\mathrm{pH} 6.5$ with $100 \mathrm{mg} / \mathrm{L}$ DIC (sample 2); (D) $\mathrm{pH} 9$ with $6 \mathrm{mg} / \mathrm{L}$ polyphosphate (sample 3); and (E) pH 6.5 with $6 \mathrm{mg} / \mathrm{L}$ polyphosphate (sample 4); (F) $\mathrm{CuO}$ standard (dotted line). oxide) within the near surface. As opposed to $\mathrm{CuO}$ in partially filled $\mathrm{d}^{9}$ configuration, the edge structure indicates the copper is in a filled $\mathrm{d}^{10}$ configuration. The spectrum in Figure 7A, which covers the oxygen $\mathrm{K}$ edge region, is indicative of a small amount of $\mathrm{Cu}_{2} \mathrm{O}$ or oxygen impurity oxygen-containing complex on the clean copper sample. As a reference, Figure 7F shows the corresponding oxygen $\mathrm{K}$-edge structure of a $\mathrm{CuO}$ standard with multiple features at 530,534 , and $539 \mathrm{eV}$ (the first peak is assigned to a $1 \mathrm{~s} \rightarrow 3 \mathrm{e}_{\mathrm{g}}$ transition, wherein the latter originates from the $\mathrm{O} 2 \mathrm{p}$ and partially filled $\mathrm{Cu}(\mathrm{II}) 3 \mathrm{~d}$ states). Our clean copper sample shows an absence of these features. Thus, based on both $\mathrm{Cu} \mathrm{L-}$ edge and oxygen $\mathrm{K}$-edge spectra, the as prepared copper is relatively clean and agrees well with the results shown by AFM.

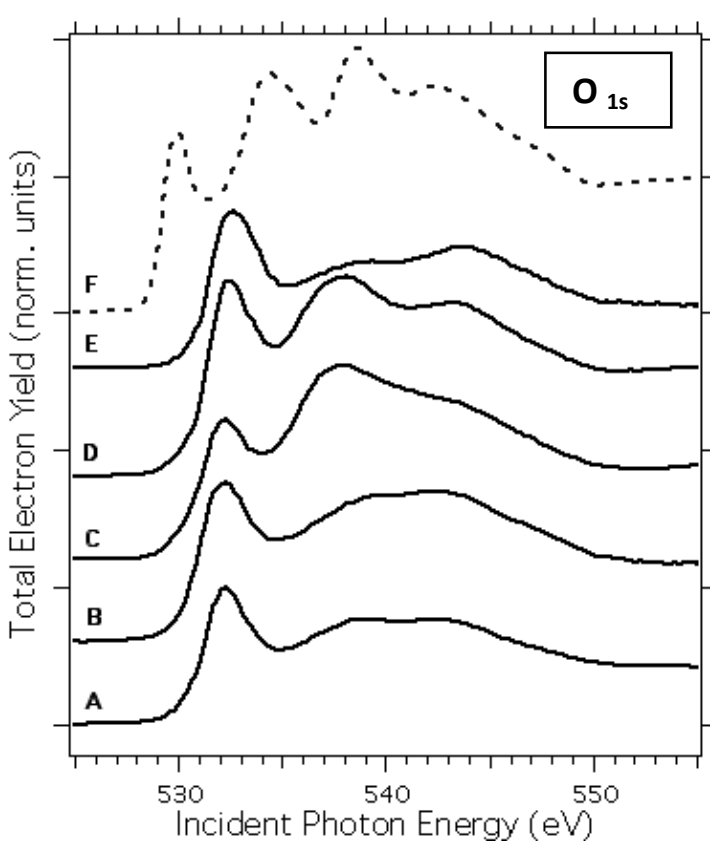

Figure 7. Total electron yield NEXAFS spectra of treated samples in the energy range of the oxygen $\mathrm{K}$ absorption edge: (A) clean copper surface. Changes of copper surface after immersion in water for $24 \mathrm{~h}$ at (B) pH 9 with $100 \mathrm{mg} / \mathrm{L}$ DIC (sample 1), (C) pH 6.5 with $100 \mathrm{mg} / \mathrm{L}$ DIC (sample 2); (D) $\mathrm{pH} 9$ with $6 \mathrm{mg} / \mathrm{L}$ polyphosphate (sample 3); and (E) pH 6.5 with $6 \mathrm{mg} / \mathrm{L}$ polyphosphate (sample 4); (F) $\mathrm{CuO}$ standard (dotted line). 
The NEXAFS spectra from copper surfaces after immersion in water at $\mathrm{pH} 9$ (sample 1) and $\mathrm{pH} 6.5$ (sample 2) with $100 \mathrm{mg} / \mathrm{L}$ DIC show distinct differences compared to the clean copper sample. Figures 6(B) and 6(C) (corresponding to Figures 7(B) and 7(C)) show $\mathrm{Cu}$ L-edge [O K-edge] spectra correspond to sample 1 (Figure 2) and sample 2 (Figure 3), respectively. As observed in Figures 7 (B) and (C), there is little change in the $\mathrm{O} \mathrm{K}$-edge spectra. Most notably, there is an apparent lack of $\mathrm{CuO}$ formation on the surface (compared with Figure 7(F)). For the high carbonate alkalinity of DIC ( $\mathrm{pH}$ 9) of sample 1, the $\mathrm{Cu}$ L-edge structure shows a broadening of both $\mathrm{L}_{\text {III }}$ and $\mathrm{L}_{\text {II }}$ absorption edges. The clean $\mathrm{Cu}$ peak (Figure 6 (B)) at $934 \mathrm{eV}$ has split into multiple peaks ( 930-935). For the pH 6.5 sample (Figure 6 (C); sample 2), NEXAFS show a similar, but slightly decreased broadening of the $\mathrm{Cu}$ edge. Comparing these results with the changes shown by AFM, it is apparent that the increased carbonates are forming surface $\mathrm{Cu}$-complexes without oxidizing further $\left(\mathrm{Cu}\right.$ or $\left.\mathrm{Cu}_{2} \mathrm{O} \rightarrow \mathrm{CuO}\right)$. Based on the increased RMS roughness in sample 3 due to precipitation of sodium salts at lower $\mathrm{pH}$, the decrease in the copper absorption width may indicate a partial passivation, and corresponding decrease in the formation of $\mathrm{Cu}$-complexes of the sample surface.

Finally, NEXAFS spectra from copper surfaces after immersion in water at $\mathrm{pH} 9$ (sample 1) and $\mathrm{pH} 6.5$ (sample 2) with $6 \mathrm{mg} / \mathrm{L}$ hexametaphosphate show only small differences compared to the clean copper sample. Figure 6(D) and 6(E) [corresponding with Figure 7(D) and 7(E)] show $\mathrm{Cu}$ L-edge [O K-edge] spectra for treated sample 3 (Figure 4) and sample 4 (Figure 5), respectively. As evidenced in Figure 7(D) and 7(E), again there are small changes in the $\mathrm{O}$ K-edge spectra, including an apparent lack of $\mathrm{CuO}$ formation on the surface as above for the high DIC samples. Moreover, except for a small broadening, the $\mathrm{Cu}$ L-edge structure is almost identical for $\mathrm{L}_{\mathrm{III}}$ and $\mathrm{L}_{\mathrm{II}}$ absorption edges of the clean copper sample. This indicates that despite the phosphate treatment of the surfaces both at $\mathrm{pH} 9$ (sample 3) and pH 6.5 (sample 4) the chemical composition of the $\mathrm{Cu}$ bulk and interface remains the same, compared to the original clean copper sample. Based on AFM results which revealed the formation of aggregated clusters of small adsorbates and corres-ponding RMS roughness, the NEXAFS results of the same samples indicate that the adsorbates are not Cu-related complexes. Rather, the underlying copper remains chemically intact.

\section{Discussion}

Side-by-side comparisons of the AFM images of various surface treatments at different immersion intervals provide new insight on the role of polyphosphates, DIC and $\mathrm{pH}$ in surface passivation or corrosion. As a frame of reference, the untreated surface of Figure 1 can be compared to each of the sets of AFM images, furnishing a baseline of the expected surface morphology for untreated copper. Evidence of an increase in pitting was not observed for surfaces treated with water samples 1 $(\mathrm{pH} 9)$ and $2(\mathrm{pH} \mathrm{6.5)}$, with the addition of $100 \mathrm{mg} / \mathrm{L}$ DIC, thus increased alkalinity from bicarbonate was demonstrated to inhibit corrosion of copper in agreement with previous reports. ${ }^{2}$ The AFM images in Figures $\mathbf{2}$ and $\mathbf{3}$ display the surface deposits of different chemical nature; however, there was no clear evidence of an increase in the density of surface pits due to corrosion. The characteristic facets and angular morphology of the crystals viewed in Figure 3 can be attributed to the precipitation of salt crystals.

Changes due to corrosion were observed for the surfaces of copper with lower levels of DIC, even with the addition of hexametaphosphate, as disclosed in the AFM images of Figures 4 and 5. Changes attributable to corrosive pitting were more readily apparent and advanced at $\mathrm{pH} 9$ than was observed for surfaces treated at $\mathrm{pH}$ 6.5. An interchange between particulate deposition and corrosive pitting was evident for surfaces treated with water at $\mathrm{pH} 6.5$ (sample 4). With addition of high levels of DIC, consistent trends for surface deposits were observed as a function of $\mathrm{pH}$ and phosphate levels as previously reported, ${ }^{8}$ however the morphology, thickness and composition of deposits showed subtle yet detectable differences at the nanoscale.

The NEXAFS results indicate that there is a lack of $\mathrm{CuO}$ formation in all of the $24 \mathrm{~h}$ samples; only small amounts of $\mathrm{Cu}_{2} \mathrm{O}$ were observed. Previous reports show that a stable layer of cuprous oxide is formed after immersion intervals of 60 days or longer. ${ }^{31}$ Whereas the addition of DIC resulted in formation of some $\mathrm{Cu}$ complexes at the surface, the addition of hexametaphosphate left the copper surface relatively unchanged compared to the clean copper sample. However, understanding the details of the chemical composition of the surface adsorbates through other characterizations may provide a clearer picture of the nature and mechanism of copper corrosion as well as the routes for producing passivating surface layers of mineral deposits. 


\section{Conclusions}

Considering the complex interactions at the surfaceliquid interface of copper for various $\mathrm{pH}$ and water treatment conditions, further research remains to be addressed. By judiciously choosing certain concentrations of DIC and polyphosphates for these initial investigations, rich information about the evolution of surface structures can be gained by studies with incremental changes in $\mathrm{pH}$, solution concentration and immersion intervals. This report furnishes a practical framework for selecting experimental parameters which markedly influence the surface changes that occur during water corrosion of copper. By combining approaches for qualitative and quantitative surface characterrizations, including both AFM and NEXAFS, a predictive molecular-level model may be developed for understanding the interplay between anions, salts, organic agents, DIC and $\mathrm{pH}$ for corrosion processes.

\section{Acknowledgments}

The authors gratefully acknowledge financial support from the National Science Foundation Career Award Program (CHE-0847291) and Presidential Early Career Award for Scientists and Engineers (PECASE). PTS acknowledges partial support from NSF-CHE-0615606 and from the EFRC "Center for Atomic Level Catalyst Design” (DOE-DE-SC0001058).

\section{References}

[1] Barceloux, D. G. Journal of Toxicology - Clinical Toxicology 1999, 37, 217-230. doi:10.1081/CLT100102421

[2] Lytle, D. A.; Schock, M. R. Journal of American Water Works Association 2008, 100, 115.

[3] Lebrini, M.; Bentiss, F.; Chihib, N. E.; Jama, C.; Hornez, J. P.; Lagrenee, M. Corros. Sci. 2008, 50, 2914-2918. doi:10.1016/j.corsci.2008.07.003

[4] Ramesh, S.; Rajeswari, S.; Maruthamuthu, S. Appl. Surf. Sci. 2004, 229, 214-225. doi:10.1016/j.apsusc.2004.01.063

[5] Laamari, M. R.; Derja, A.; Benzakour, J.; Berraho, M. J. Electroanal. Chem. 2004, 569, 1-6. doi:10.1016/j.jelechem.2003.12.045

[6] Amar, H.; Benzakour, J.; Derja, A.; Villemin, D.; Moreau, B. J. Electroanal. Chem. 2003, 558, 131139. doi:10.1016/S0022-0728(03)00388-7

[7] Truc, T. A.; Pebere, N.; Hang, T. T. X.; Hervaud, Y.; Boutevin, B. Corros. Sci. 2002, 44, 2055-2071. doi:10.1016/S0010-938X(02)00013-6
[8] Lewandowski, B. R.; Lytle, D. A.; Garno, J. C. Langmuir 2010, 26, 14671. doi:10.1021/1a102624n

[9] Zhe, Y.; Pehkonen, S. O. Water Sci. Technol. 2004, 49, 73-81.

[10] Edwards, M.; Hidmi, L.; Gladwell, D. Corros. Sci. 2002, 44, 1057-1071. doi:10.1016/S0010938X(01)00112-3

[11] Telegdi, J.; Shaglouf, M. M.; Shaban, A.; Karma'n, F. H.; Betroti, I.; Mohai, M.; Kalman, E. Electrochimica Acta 2001, 46, 3791-3799. doi:10.1016/S0013-4686(01)00666-1

[12] Vastag, G.; E. Szöcs; Shaban, A.; Kálmán, E. Pure Appl. Chem. 2001, 73, 1861-1869. doi:10.1351/pac200173121861

[13] Wang, R. Appl. Surf. Sci. 2004, 227, 399-409. doi:10.1016/j.apsusc.2003.12.019

[14] Xu, L.; Chan, K.; Fang, H. H. P. Materials Characterization 2002, 48, 195-203. doi:10.1016/S1044-5803(02)00251-6

[15] Mu, G.; Li, X. Journal of Colloid and Interface Science 2005, 289, 184-192.

doi:10.1016/j.jcis.2005.03.061

[16] Olivares-Xometl, O.; Likhanova, N. V.; Dominguez-Aguilar, M. A.; Hallen, J. M.; Zamudio, L. S.; Arce, E. Appl. Surf. Sci. 2006, 252, 21392152. doi:10.1016/j.apsusc.2005.03.178

[17] Skolnik, A. M.; Hughes, W. C.; Augustine, B. H. Chemical Educator 2000, 5, 8-13. doi:10.1007/s00897990350a

[18] Kleber, C.; Hilfrich, U.; Schreiner, M. Appl. Surf. Sci. 2007, 253, 3712-3721. doi:10.1016/j.apsusc.2006.08.005

[19] Aastrup, T.; Wadsak, M.; Schreiner, M.; Leygraf, C. Corros. Sci. 2000, 42, 957-967. doi:10.1016/S0010-938X(99)00125-0

[20] Li, J.; Lampner, D. Colloids Surf., A 1999, 154, 227-237. doi:10.1016/S0927-7757(98)00901-7

[21] Sanchez, J.; Fullea, J.; Andrade, C.; Gaitero, J. J.; Porro, A. Corros. Sci. 2008, 50, 1820-1824. doi:10.1016/j.corsci.2008.03.013

[22] Martin, F. A.; Bataillon, C.; Cousty, J. Corros. Sci. 2008, 50, 84-92. doi:10.1016/j.corsci.2007.06.023

[23] Borch, T.; Camper, A. K.; Biederman, J. A.; Butterfield, P. W.; Gerlach, R.; Amonette, J. E. Journal of Environmental Engineering 2008, 10, 835-844. doi:10.1061/(ASCE)07339372(2008)134:10(835) 
[24] Telegdi, J.; Shaglouf, M. M.; Shaban, A.; Karman, F. H.; Betroti, I.; Mohai, M.; Kalman, E. Electrochim. Acta 2001, 46.

[25] Kleber, C.; Wiesinger, R.; Schnoller, J.; Hilfrich, U.; Hutter, H.; Schreiner, M. Corros. Sci. 2008, 50, 1112-1121. doi:10.1016/j.corsci.2007.12.001

[26] Gurevich, A. B.; Bent, B. E.; Teplyakov, A. V.; Chen, J. G. Surf. Sci. 1999, 442, L971-L976. doi:10.1016/S0039-6028(99)00913-9

[27] Zhang, X.; Pehkonen, S. O.; Kocherginsky, N.; Ellis, G. A. Corros. Sci. 2002, 44, 2507-2528. doi:10.1016/S0010-938X(02)00021-5

[28] Vargas, I. T.; Alsina, M. A.; Pastén, P. A.; Pizarro, G. E. Corros. Sci. 2009, 51, 1030-1037. doi:10.1016/j.corsci.2009.02.014
[29]Merkel, T. H.; Pehkonen, S. O. Corros. Eng. Sci. Technol. 2006, 41, 21-37. doi:10.1179/174327806X94009

[30] Cong, H.; Michels, H. T.; Scully, J. R. J. Electrochem. Soc. 2009, 156, C16-C27. doi:10.1149/1.2999351

[31] Shim, J. J.; Kim, J. G. Mater. Lett. 2004, 58, 20022006. doi:10.1016/j.matlet.2003.12.017

[32] Klapetek, P.; Necas, D.; Czech Metrology Institute: Czech Republic, 2007, http://gwyddion.net/

[33] The J. Bennett Johnston Sr. Center for Advanced Microstructures and Devices, Baton Rouge, LA http://www.camd.lsu.edu/

[34] Otmacic, H.; Telegdi, J.; Papp, K.; Stupnisek-Lisac, E. J. Appl. Electrochem. 2004, 34, 545-550. doi:10.1023/B:JACH.0000021873.30314.eb 